DOI: https://doi.org/10.46991/AFA/2021.17.2.085

\title{
MYENGLISHLAB AS ONE OF THE GROUNDBREAKING BLENDED LEARNING TOOLS
}

\author{
Marianna Ohanyan* \\ Yerevan State University
}

Online learning is one of the most rapidly growing trends in educational use of digital technologies. The article touches upon the importance of MyEnglishLab as one of the newest tools for blended English language learning. Due to the pandemics of the 2020 many learners began to implement different tools of digital technology to an increasing extent. An effective and appropriate tool for learning English aimed at developing communication skills allows to increase individualization of educational activity, to optimize mastering language structures and grammatical rules, and also to overcome some obstacles of both oral and written competences of the students. An interactive platform is one of the newest blended learning tools that combines different English language learning activities in a variety of formats. It is a web-based system providing learners 24 hours a day, 7 days a week online access to the teacher-managed course content, supports different learning styles, provides students with a large number of supervised practices. The platform MyEnglishLab contains lexical and grammatical tasks, audio materials listening and reading as well as watching videos. Tasks are performed in three stages: the formation of lexical and grammatical skills; improvement of language skills and using those phrases and sentences that were consolidated in the first stage in the dialogue with a computer; development of skills to use lexical and grammatical knowledge acquired during the previous two stages. The platform has options for choosing the number of attempts to perform both test exercises and training.

In this article we present a research carried out among the freshmen of Yerevan State University Faculty of European Languages and Communication.

Keywords: online teaching and learning, language learning, blended learning, social interaction, the English language, interactive platform, MyEnglishLab. 


\section{Introduction}

The English language undergoes significant changes in the last few years, and there is a need to solve a number of didactic problems for students of philology: to develop writing and reading skills by using materials of different levels of complexity, enhance effective listening skills based on authentic audio texts; improve writing skills through replenishing the vocabulary (both active and passive) of modern foreign language with special attention to cross-cultural communication which reflects a certain stage of development, to enrich the knowledge of the students with cultural knowledge, which includes speech etiquette, features of culture and traditions of the country, whose language is being studied, improve knowledge of grammar by performing tests, to form a stable motivation of cognitive activity, to form skills of global thinking, instill the need of using English for the purpose of real communication through the implementation of the latest techniques and technologies.

The most effective way of learning English is first of all solving didactic goals which can be achieved through the use of blended learning. However, the problem of using the latest multimedia technologies that allow to combine all types of materials in a single resource for effective training of students under the guidance of a teacher, remains insufficiently studied. It determines the relevance of the chosen topic. We should hasten to add that the effective platform MyEnglishLab can be integrated with the Moodle system which finally enabled to distribute the study materials to students in the experimental group within one system.

The purpose of our study is to analyze the role and importance of the interactive platform MyEnglishLab in the process of mixed learning of English by students of philology. The objectives of the present study are to provide the students with available material and information. There are different approaches to defining the essence of the concept of "blended learning". Kurkan offers the combination of traditional formal learning tools - working in classrooms, studying theoretical material - with informal ones, for example, with discussions via e-mail and Internet conferences (Kurkan, 2015, p.489). Purnima uses the term "blended learning" to describe solutions in which she considers important to combine different ways of presenting training content, such as courses based on Web technologies, EPSS (Educator Performance and Support System) and knowledge management techniques. She also uses it to describe learning that combines different types of training activities, including face-to-face training, online e-learning and self-learning in the workplace 
(Purnima, 2002). A blend is an integrated strategy for delivering on promises about learning and performance. Blending involves a planned combination of approaches such as coaching by a supervisor, participation in an online class, breakfast with colleagues, competency descriptions, reading on the beach, reference to a manual, collegial relationships, and participation in seminars, workshops, and online communities (Rossett, Douglis \& Frazee, 2003). Roger Schank - one of the most highly respected thinkers, writers and speakers in the training, learning, and E-learning community, demonstrates steps and strategies proven to excite employees, make them want to learn, and decrease training costs while increasing productivity. Schank's approach also involves learning from failure. He defines blended learning as the use of E-learning and classroom learning (Schank, 2002). Moebs and Weibels define blended learning as a "combination of distance and traditional communication in integrated learning activities"(Moebs \& Weibezahl, 2006). Blended learning provides the possibility of using different methods of presenting the material for work in a traditional classroom, combined with distance learning to achieve the objectives of the course. At the same time Graham defines blended learning as an approach that integrates traditional learning and computer-mediated learning in a pedagogical environment (Graham, 2005). The model of blended learning in the modern educational environment can be divided into three main components that function in a constant relationship: 1. Full-time training (faceto-face) which presupposes the traditional format of classroom (teacher student); 2. Self-study learning which is the independent work of the students; 3. Online learning (online collaborative learning) with the work of students and teachers online which is one of the modern tools for blended learning all over the world today.

\section{On some effective methods of blended learning}

The object of research is the use of the interactive platform MyEnglishLab in English classes as the main element of blended learning. Descriptive, comparative and generalizing methods are used while carrying out the following research. Analysis of lexicographic definitions with elements of componential analysis is used to determine the meaning of the concept "mixed teaching".

MyEnglishLab - an innovative online platform providing thousands of different activities with learning English in various formats, provides individual feedback; allows to perform tasks 24/7; supports different learning styles; 
provides students with a huge number of controlled computer-based practices anywhere and any time. The platform contains the following aspects:

- lexical, aimed at the formation of lexical competence through learning a certain stock of lexical units, idioms and proverbs and using them in their own speech. Lexical competence combined with socio-cultural and sociolinguistic awareness of the students is a reliable basis for the implementation of speech.

- grammatical, the goal of which is completing different sentences with the correct tense forms of the verbs in brackets and finding the grammatical mistakes, etc.

- writing, when the learners are expected to write some symbols characterizing The Armenians and the British (e.g. Golden Eagle as the national animal of Armenia, Lion as the National Animal of England, etc.). As a result of regular training in written expression, students gain experience in choosing the necessary words and phrases. It is well known that oral communication can be developed through prepared speech, for written speech is often a prerequisite for the development of internal speech.

- listening to a passage and trying to write the plot of the text is a very effective exercise for not only developing the learners' listening competences but also memorizing the key words and syntactic constructions of the audiotext. On the other hand the effectiveness of listening is related to mandatory performance of auditory skills, which helps to achieve the understanding of the audiotext as a whole.

- reading which presupposes the reading of a passage, answering the questions and choosing the correct answer, selecting the best summary and completing the sentences with the words or phrases in the text. Reading is one of the most important types of communicative and cognitive activities.

- watching the video materials which increases the level of motivation to learn a foreign language (in our case English), gives an opportunity to work with authentic samples in English.

Implementation of tasks on the interactive platform MyEnglishLab is a three-stage process:

Stage 1 is the formation of lexical and grammatical skills on the basis of topical texts. At this stage, students learn new vocabulary and grammar, improve language skills of listening and repeating phrases and sentences.

Stage 2 is the improvement of language skills through using the phrases and sentences assimilated by students at the first stage of learning. Students 
perform tasks aimed at a kind of computer verification of options with the correct answer.

Stage 3 is the development of skills for using lexical and grammatical knowledge acquired at the previous two stages. Students are offered assignments using authentic audio and video materials. In addition to exercises, the teacher can also assign a test based on the material already covered. This gives an opportunity to check the quality of the knowledge of a significant number of students for a very limited time; assessment in this case is more objective and at a pre-planned level. The teacher can see the results of the tasks on the personal page of each student, which contains information on the number of completed tasks, the percentage of the correct answers, and finalize his/her assessment. All grades can be exported, giving a chance for archiving the results and student involvement in the performance of the tasks.

Working with a computer not only increases the students' motivation to learn, but also avails the teacher of an opportunity to obtain additional information about the work of each student: how much time he spent on each task, the number of attempts, etc. Every time a student makes a mistake, MyEnglishLab responds with feedback and encourages students to learn from their mistakes and try again. It is important to note that such work can significantly reduce the time for inspection tasks, track every individual student and adjust the degree of complexity of the tasks. In addition, the computer allows to completely eliminate one of the most important reasons for a negative attitude to learning - learning failure due to misunderstanding of the material or "gaps" in knowledge. MyEnglishLab is based on the principles of individualization and differentiation (the teacher can choose and offer tasks of a certain complexity). Among the main didactic functions implemented by MyEnglishLab is cognitive, developmental (promotes development of such necessary cognitive processes as perception, logical thinking, memory, imagination), training (possibility to train independently and test your level of knowledge and skills with certain topics, refine them and complete the proposed tasks), diagnostic (the teacher is able to quickly control and find out the level of mastering the topic by students), communicative (stimulating the use of oral speech with students which helps them overcome the fear of failing).

\section{Conclusion}

The main task of higher education today is providing effective and high-quality training of students which is impossible to accomplish in the modern world 
without the use of modern approaches to learning, for they make classes productive and interesting not only for students who are free to use modern electronic devices but also for teachers who try to optimize the learning process management.

As our research study has shown, students of philology using MyEnglishLab in their English courses reached better results in grammar, vocabulary, reading and listening skills through modern and efficient learning digital environment in comparison with students using conventional paperbased materials. We can consider it not only a question of acquiring certain skills, but also of reformulating the relationship between knowledge, practice and sustainability experience. One of the modern methods of teaching foreign languages to philologists with the active use of information technologies is blended learning with an efficient use of the interactive platform MyEnglishLab. The latter is an effective and appropriate tool for blended learning of a foreign language (in our case English) aimed at developing communicative abilities, which allows to increase the individualization of educational activities, to optimize the acquisition of language structures and grammatical rules, as well as to overcome the monotony of the lesson. Using the interactive platform MyEnglishLab helps to fulfil a range of methodological, didactic, pedagogical and psychological tasks and increases the efficiency of the teaching process, develops different types of language activities, serving as a kind of steady and safe motivation for foreign language students of philology.

\section{References}

Graham, C. R. (2005). Handbook of blended learning: global perspectives, local designs. San Francisco, CA: Pfeiffer Publishing.

Kurkan, N. V. (2015). Effektivnost' smeshannogo obucheniya pri obuchenii inostrannomu yazyiku $\mathrm{V}$ usloviyah sovremennogo obrazovaniya [Efficiency of Blended Learning in Teaching a Foreign Language in Conditions of Modern Education]. Young Scientist, 5, 488- 491.

Moebs, S., \& Weibelzahl, S. (2006). Towards a good mix in blended learning for small and medium sized enterprises. Outline of a Delphi Study. Proceedings of the Workshop on Blended Learning and SMEs held in conjunction with the $1^{\text {st }}$ European Conference on Technology Enhancing Learning, (pp.1-6).

Purnima, V. (2002). Blended learning models. Learning Circuits. ASTD's Source for E-Learning. Retrieved from http://www.purnima- 
valiathan.com/wp-content/uploads/2015/09/Blended-Learning-Models2002-ASTD.pdf.

Rossett, A., Douglis F., \& Frazee V. R. (2003). Strategies for building blended learning. Retrieved from https://www.researchgate.net/publication/228550955_Strategies_for_Building_Blended_Learning Schank, C. R. (2002). Designing world-class e-learning: How IBM, GE, Harvard Business School, and Columbia University are succeeding at elearning. Centers for Teaching Excellence - Book Library.190. Retrieved from https://digitalcommons.georgiasouthern.edu/ct2-library/190

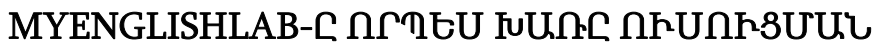 UกU.SUSUR Uh,Qก8}

\section{Uuphuiqqu Ohuidjuia}

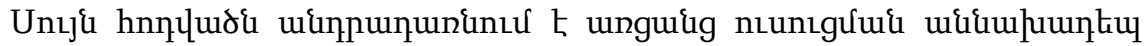

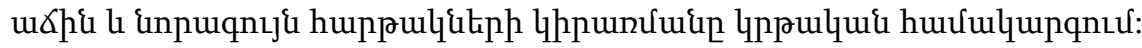

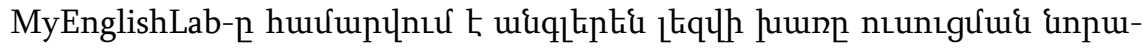

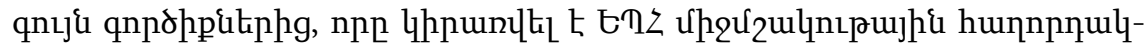

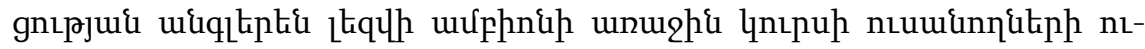

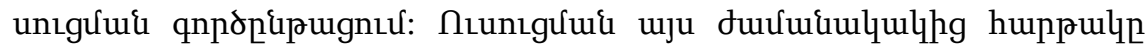

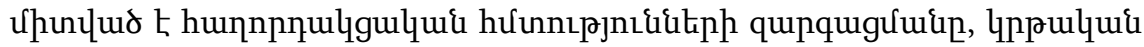

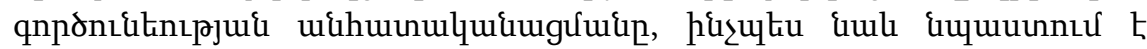

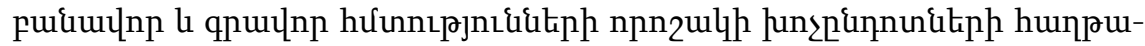

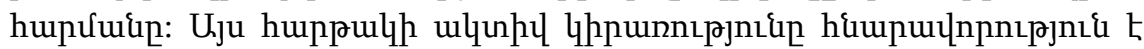

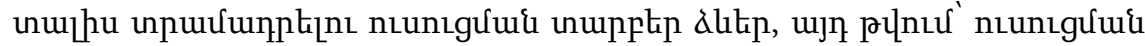

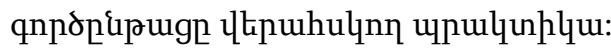

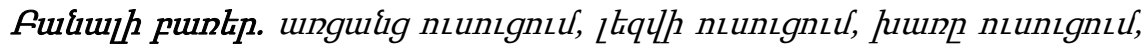

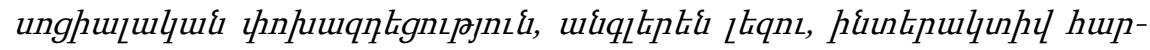
puly, MyEnglishLab: 